\title{
Educational Leadership in Teaching Excellence: The University of Guelph EnLITE Program
}

Andrea Buchholz and Janet Wolstenholme, University of Guelph

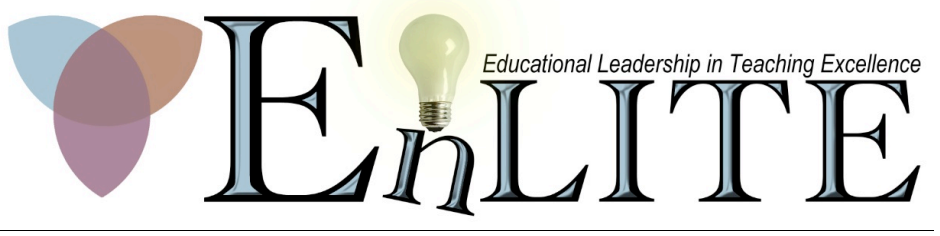




\begin{abstract}
Educational Leadership in Teaching Excellence (EnLITE) is a one-year program (Sept to Aug) at the University of Guelph. It is designed to engage mid-career faculty in the theory, practice and scholarship of teaching and learning, and to establish and support a faculty community of practice which provides mentorship and leadership in teaching and learning in higher education.

Divided into two subprograms, faculty participants enrolled in EnLITE I critically examine and discuss scholarly topics on teaching and learning and in their own disciplines; collaborate with a teaching mentor; engage in classroom observation and peer feedback; and demonstrate commitment to continual improvement through completion of an individual program learning plan, critically reflective teaching practice, and creation of an electronic teaching dossier (ePortfolio). Participants meet twice monthly, in the larger cohort and in smaller groups called "Action Learning Sets."

Those wishing to engage in pedagogical research may concurrently or subsequently enrol in EnLITE II, also a one-year program. Participants in EnLITE II develop, implement and disseminate research on teaching and learning in higher education, and are expected to demonstrate how results of their research inform their teaching practice. Participants meet monthly in Action Learning Sets.

Each participant in EnLITE I and II embarks upon a process unique to their individual goals and objectives. The expected time commitment for each program is approximately 5 hours per week. Participants' progress is evaluated on a pass/fail basis against their own individual learning plan, and program outcomes. We see commitment to teaching and learning as being rewarded both in the classroom from students, as well as faculty satisfaction and increasingly, in tenure and promotion decisions.
\end{abstract}

\title{
Why a Faculty Development Program in Teaching?
}

Learning to teach does not end, or in some cases, even begin, in graduate school. Consistent with the Learning to Live: Learning for Life theme of the 2013 meeting of the Society for Teaching and Learning in Higher Education, we propose several reasons universities may wish to develop a faculty development program in teaching.

Structured training of university instructors makes a difference. In the largest study of its kind to date, Gibbs and Coffey (2004) studied the effectiveness of teacher training programs in 22 universities across 8 different countries. Faculty who had participated in such programs were more likely to adopt a learner-centred teaching practice, and their teaching skills and global teaching effectiveness scores improved. Student learning was impacted positively by faculty engagement in these initiatives. But perhaps the most interesting finding was that faculty who did not engage in such programs decreased the extent to which they adopted a learner-centred teaching approach, and actually became more reliant on instructor-centred teaching practices.

Closer to home, Britnell and colleagues (2010) conducted a survey of 876 faculty members in 6 publicly funded universities in Ontario. Fifty-nine percent of respondents felt it was important/very important for their institution's teaching and learning centres to offer help with research on teaching. Seventy percent felt the same about providing opportunities to make contact with peers and to network. Despite this, fewer than half (46\%) felt their university strongly supports/supports their growth as a teacher. 
Finally, faculty development programs are becoming increasingly common. Along with ours, four other universities across Canada (York University, University of Windsor, University of British Colombia and University of Alberta) currently offer faculty members structured training programs in teaching and learning in higher education. Two of these (York and Windsor) as well as our institution have obtained international accreditation of their programs by the U.K.-based Staff and Educational Development Association (SEDA, www.seda.ac.uk), a professional association "promoting innovation and good practice in higher education."

\section{The Educational Leadership in Teaching Excellence (EnLITE) Program}

We reasoned, given that (i) structured training of university faculty positively impacts student learning, (ii) faculty would like support networking with peers and with the scholarship of teaching and learning (SoTL), and (iii) faculty development programs are increasingly common in Canada, the University of Guelph should create a structured faculty development program centred on educational leadership. As depicted in Figure 1, we envisioned educational leadership to be at the intersection of exemplary teaching and learning, a faculty community of practice, and engagement in SoTL.

And so was born, in 2009, the Leadership in Teaching program. It has since evolved into EnLITE, a one-year program (September to August) aimed at mid-career faculty members. EnLITE is designed to engage faculty in the theory, practice and scholarship of teaching and learning, and to establish and support a faculty community of practice which provides mentorship and leadership in teaching and learning in higher education. In the 2012-2013 academic year, we subdivided the program into EnLITE I and EnLITE II, both of which have since received SEDA accreditation.

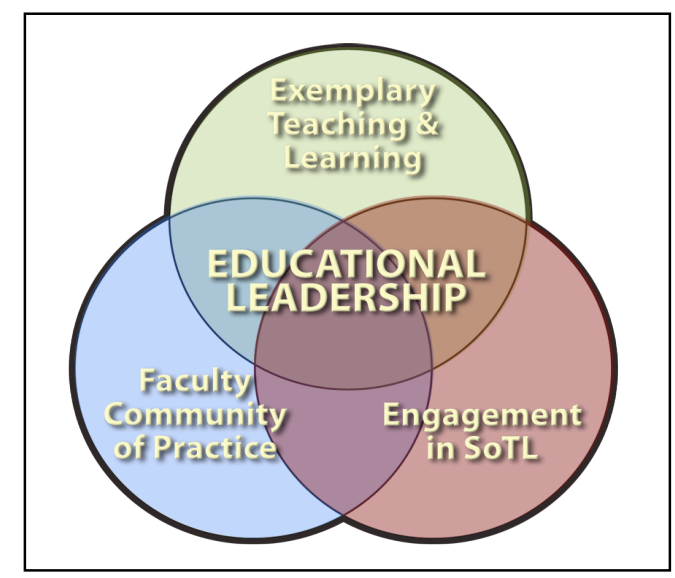

Figure 1 The University of Guelph EnLITE (Educational Leadership in Teaching Excellence) program fosters educational leadership, which is at the intersection of exemplary teaching and learning, a faculty community of practice, and the scholarship of teaching and learning

\section{EnLITE I}

Consistent with the SEDA Named Award "Enhancing Academic Practice in Disciplines," participants in EnLITE I critically examine and discuss scholarly topics on teaching and learning 
in higher education and in their own disciplines; collaborate with a teaching mentor; engage in classroom observation and peer feedback; and demonstrate commitment to continual improvement through completion of an individual program learning plan, critical reflections on their teaching practice, development of an electronic teaching dossier (ePortfolio), and a pedagogical presentation to the EnLITE cohort. Participants meet twice per month: once as a larger cohort, and once in smaller groups called "Action Learning Sets" (Pay, 2003).

At the beginning of the program, each participant develops an independent learning plan, which clearly outlines and details how and when they will meet the program's learning outcomes (for program outcomes please see: http://www.opened.uoguelph.ca/TSS/educational development/ELITE.aspx). Each learning plan is uniquely tailored to meet the participants' individual goals and objectives, and includes a general timeline for achievement of the specified program outcomes. Participants present, discuss and get feedback on their independent learning programs from the EnLITE committee and cohort members.

During the monthly cohort meetings, participants are required to read one to two assigned readings from the pedagogical literature, and to find and read a 'matching' article from their own discipline. The latter activity is designed to encourage participants to draw connections between educational theory and educational activities in their own disciplines.

During the monthly Action Learning Sets, participants meet in smaller groups of 3 or 4. Each participant has approximately 30 minutes to share a teaching-related issue or question and/or to discuss their progress as regards their individual learning plan. This is followed by reflections and feedback from the other Action Learning Set participants. The "action" component requires the participant to articulate an objective and plan related to the teaching issue or question, and which is then reviewed at the next Action Learning Set meeting.

Throughout the program, participants reflect upon their progress and readings by completing monthly critically reflective journal entries. Guiding questions provide some context to these entries. At the end of the program, participants review past entries, and prepare a "metareflection" which draws upon the key observations, interpretations and transformations that they have made in relation to their development as an instructor, over the course of the program.

Each participant engages in a classroom teaching observation exercise. Two observations are required, one as an observer and another as an observee (either within or outside of participants' own discipline). At least once per month, participants also collaborate with a mentor to explore pedagogical principles and practices related to their independent learning plans; they are required to reflect upon their experiences associated with the classroom observation and mentorship process in one or more of their monthly journal entries.

In the latter part of the program, and at one of the monthly cohort meetings, each participant leads a discussion on a topic of interest in the teaching and learning literature.

Lastly, each participant develops an ePortfolio which highlights their teaching accomplishments and provides evidence of, and reflections on, their experiences in the EnLITE I program. The portfolio includes, but is not limited to, a teaching dossier, individual learning plan, monthly reflections, other content the participant deems relevant to their learning and the final meta-reflective report. Participants are expected to review, and provide feedback on, each other's ePortfolio.

\section{EnLITE II}

Consistent with the SEDA Named Award "Enhancing Research Practice," those participants wishing to engage in pedagogical research may enrol in EnLITE II concurrently with, or 
subsequent to, EnLITE I. Also a one-year program (September to August), participants in EnLITE II are expected to develop, implement and disseminate research on teaching and learning in higher education; to demonstrate how results of their research inform their teaching practice; and to collaborate with colleagues and mentors to build an active learning and support community. The following are a couple of examples of research projects undertaken by past participants:

- Participating in an Optional Lab Experience Enhances Self-Perceived Learning of Nutrition Majors (presented at the University of Guelph Teaching and Learning Innovations Conference);

- Community Engaged Learning Techniques from a Traditional Aboriginal Pedagogy Improves Learning in a Large-Enrolment University Biology Class (also presented at the University of Guelph Teaching and Learning Innovations Conference)

Participants meet once a month in Action Learning Sets with other members of EnLITE I and II, to discuss their individual learning plans and research projects. The Action Learning Sets are key to EnLITE II providing space for critically discussing current research issues, challenges faced and to get feedback from a cross discipline perspective from the set members.

\section{EnLITE I and EnLITE II}

The anticipated time commitment for each program is approximately 5 hours per week. Each faculty participant embarks upon a process that is unique to their individual goals and objectives. Outcomes for both programs are evaluated on a pass/fail basis by the EnLITE committee comprised of an educational developer and three faculty members who have successfully completed EnLITE I and II.

Each participant meets one-on-one with the EnLITE committee three times during the program - at the beginning, midway, and at the end. Meeting with each participant individually has been invaluable for the growth of the program. In addition to discussing with the committee the progress through the program, the meeting provides participant feedback on the program, in "real time." This process has proved useful for implementing improvements to the program and for further ideas of continued contributions to teaching and learning at our institution.

Enrolment in each program is $\$ 500$ for cost recovery, and is typically paid by the faculty participant's department and/or college.

\section{Future Directions}

In fall 2014, we will welcome our fourth cohort of faculty members into the EnLITE program. We and our colleagues are currently designing a research tool to evaluate the program. We are also exploring expanding the program to address the unique teaching and learning needs of new and senior faculty members.

\section{Authors' Biographies}

Andrea Buchholz is Associate Professor of Applied Human Nutrition at the University of Guelph, and is Academic Lead of the EnLITE program. Janet Wolstenholme is an Educational Developer and Educational Lead for EnLITE, also at the University of Guelph. They are two of four members of the EnLITE program committee, along with Professors Andy Robinson and Jeji Varghese, all of whom been involved with the program since its inception. 


\section{References}

Britnell, J., Brockerhoff-Macdonald B., Carter, L., Dawson D., Doucet, L., Evers, F., ...Wilson, J. (2010). University faculty engagement in teaching development activities Phase II. Toronto: Higher Education Quality Council of Ontario.

Gibbs, G. \& Coffey, M. (2004). The impact of training university teachers on their teaching skills, their approach to teaching, and the approach to learning of their students. Active Learning in Higher Education, 5(1):87-100.

Pay, C. (2003). Action Learning Sets. BOND, Network for International Development, Guidance Notes No. 51. 